OPEN ACCESS

Edited by:

Katerina Chatzidionysiou, Karolinska Institutet (KI), Sweden

Reviewed by:

Elena Bartoloni,

University of Perugia, Italy

HuangHsi Chen,

Chung Shan Medical University

Hospital, Taiwan

*Correspondence:

Francesco Carubbi

francescocarubbi@libero.it

Specialty section: This article was submitted to Rheumatology,

a section of the journa

Frontiers in Medicine

Received: 23 May 2020

Accepted: 28 July 2020

Published: 08 September 2020

Citation:

Pavlych V, Di Muzio C, Alunno A and Carubbi F (2020) Comparison of Rituximab Originator With CT-P10 Biosimilar in Patients With Primary Sjögren's Syndrome: A Retrospective

Analysis in a Real-Life Setting

Front. Med. 7:534.

doi: 10.3389/fmed.2020.00534

\section{Comparison of Rituximab Originator With CT-P10 Biosimilar in Patients With Primary Sjögren's Syndrome: A Retrospective Analysis in a Real-Life Setting}

\author{
Viktoriya Pavlych ${ }^{1}$, Claudia Di Muzio ${ }^{1}$, Alessia Alunno ${ }^{2}$ and Francesco Carubbi ${ }^{3 *}$ \\ ${ }^{1}$ Rheumatology Unit, Department of Biotechnological and Applied Clinical Science, School of Medicine, University of \\ L'Aquila, L'Aquila, Italy, ${ }^{2}$ Rheumatology Unit, Department of Medicine, University of Perugia, Perugia, Italy, ${ }^{3}$ COVID-19 \\ Medical Unit, Department of Medicine, ASL1 Avezzano-Sulmona-L'Aquila, San Salvatore Hospital, L'Aquila, Italy
}

Introduction: Over the last two decades, rituximab (RTX) has been widely used, albeit off-label, in primary Sjögren's syndrome (pSS). Several studies reported that B lymphocyte depletion with RTX is effective to treat some aspects within the disease spectrum, by reducing disease activity and affecting the inflammation and lymphoid organization that occur in target tissues. Notwithstanding, randomized controlled trials failed to confirm such evidence. With the recent release of several RTX biosimilars on the market, their efficacy and safety compared to the originator must be ascertained across different indications. This study aimed at comparing efficacy and safety of RTX originator and CT-P10 RTX biosimilar in pSS patients in a real-life setting.

Methods: Clinical and laboratory records of pSS patients referring to a tertiary rheumatology clinic were retrospectively evaluated. Patients having received at least two courses of either RTX originator or CT-P10 with complete data at baseline and after 12, 24, 36, and 48 weeks of treatment were enrolled. Disease activity was assessed with the EULAR Sjögren's Syndrome Disease Activity Index (ESSDAl) and its clinical version without the biological domain (clinESSDAI). Patient-reported symptoms were assessed with the EULAR Sjögren's Syndrome Patient-Reported Index (ESSPRI). Adverse events (AEs) occurring during the study period were also recorded.

Results: Nine patients who received RTX originator and eight patients who received CT-P10 were enrolled. Baseline clinical and serological features, including ESSDAI and ESSPRI, were similar in the two treatment groups. An efficient depletion of circulating $\mathrm{CD}^{+}{ }^{+} \mathrm{B}$ lymphocytes was achieved in both treatment arms. Both RTX originator and CT-P10 significantly reduced ESSDAI and clinESSDAI by week 24, and no difference between the groups was observed at any timepoint. Conversely, changes of ESSPRI overtime did not differ between the two treatment arms and were not statistically significant compared to corresponding baseline values. With regard to safety, at 48 weeks of follow-up, only four mild AEs (two in the RTX originator and two in the CT-P10 group) were observed. 
Conclusion: Our study provides the first evidence that, at 48 weeks of follow-up, RTX originator and CT-P10 display similar efficacy and safety profiles in pSS.

Keywords: primary Sjögren's syndrome, rituximab, ESSDAI, ESSPRI, biosimilar

\section{INTRODUCTION}

Primary Sjögren's syndrome (pSS) is a systemic autoimmune disease characterized by mucosal dryness in the majority of patients. General symptoms such as fatigue, weight loss, and fever, as well as extraglandular manifestations involving musculoskeletal system, skin, peripheral and central nervous system, kidneys, and lungs, occur in at least one-third of patients, increasing health care costs and affecting the quality of life (1-3). The evolution into B-cell lymphoma represents one of the main causes of decreased survival in pSS and occurs in about $5 \%$ of patients (4).

$\mathrm{B}$ cells play a major role in the pathogenesis of pSS via antibody-dependent and -independent mechanisms, and their hyperactivity, along with salivary gland infiltration and development of B-cell follicles containing germinal center-like structures, represents the hallmarks of the disease (4-7).

Therapeutic management of pSS is based on symptomatic treatment of sicca symptoms and broad-spectrum immunosuppression for systemic disease, but data concerning efficacy and safety of the therapeutic options available are often insufficient (8). Although the emergence of biological therapies has increased the therapeutic armamentarium available to treat pSS, their use in clinical practice is limited by the lack of licensing (9). Given the central role of B cells in pSS pathogenesis, a $\mathrm{B}$-cell targeting therapy represents an unarguable and intriguing therapeutic approach in this disease. Rituximab (RTX) is a chimeric murine/human IgG1 monoclonal antibody (with human kappa and IgG1 constant regions and murine lightand heavy-chain variable regions) targeting the CD20 molecule (human B lymphocyte-restricted differentiation antigen, Bp35) found on the surface of most $B$ cells, including pre-B, mature B lymphocytes, and malignant B cells, but not on stem cells, pro-B cells, normal plasma cells, or other normal tissues. There are at least four postulated mechanisms of action for RTX: complement-mediated cytotoxicity, antibody-dependent cellmediated cytotoxicity, induction of apoptosis, and saturation of the $\mathrm{Fc}$ receptors of effector cells, and all of them may contribute to the therapeutic effect in pSS $(10,11)$.

In pSS, RTX has been tested in four randomized controlled trials (RCTs) (12-15), three prospective cohort studies (1618), and one case-control study (19). It is evident from most studies that RTX has a positive impact on B-cell numbers and activity, both in the peripheral blood and in salivary glands, but the clinical efficacy of B-cell depletion therapy with RTX in pSS remains controversial (20). In particular, although the majority of studies showed efficacy in at least one of the systemic outcomes analyzed, such as global response, organ-specific response, EULAR Sjögren's Syndrome Disease Activity Index (ESSDAI) reduction, and prednisone reduction, the evidence reported by RCTs is weak. Moreover, an analysis of data from The
Trial of Anti-B cell Therapy in Patients With Primary Sjögren's Syndrome shows that RTX is not cost-effective (15). Therefore, the recent EULAR recommendations for the management of Sjögren's syndrome pointed out that the use of RTX should be reserved to selected patients with severe, refractory systemic disease (8).

RTX was the first monoclonal antibody to be approved for the treatment of some type of blood cancer and inflammatory conditions as rheumatoid arthritis, granulomatosis with polyangiitis, microscopic polyangiitis, and pemphigus vulgaris [MabThera ${ }^{\circledR}$ [Roche, Welwyn Garden City, United Kingdom] in Europe and Rituxan ${ }^{\circledR}$ [Genentech, San Francisco, CA] in the USA] $(21,22)$. As this anti-CD20 monoclonal antibody has now reached patent expiry date, biosimilar versions are in development. In particular, CT-P10 [Truxima ${ }^{\circledR}$ (Celltrion Incheon, Republic of Korea)] has recently been approved in Europe for all indications held by MabThera ${ }^{\circledR}$ (23).

Biosimilars have the potential to broaden patient access to biologics and reduce the economic burden of health care systems. During the development of a biosimilar, data that directly compare the proposed biosimilar with the reference product are required. These comparative data are generated in a stepwise hierarchical process from extensive laboratory-based structural analyses and functional assays, to clinical safety and efficacy (24). Demonstration of similarity in these trials, along with extensive evidence of similarity from other tests, allows the extrapolation of data with the reference compound to the biosimilar in other non-tested indications (25).

Several clinical trials assessing CT-P10 in follicular lymphoma and rheumatoid arthritis (26-33) and a few data concerning the real-world experience $(34,35)$ have been published so far. However, data concerning this compound in pSS are not available.

To our knowledge, no study has compared efficacy and safety of any approved RTX biosimilar to RTX originator in pSS patients. Therefore, the aim of this retrospective, observational, single-center study was to compare the efficacy and safety of CTP10 (Truxima ${ }^{\circledR}$ ) with RTX originator (MabThera ${ }^{\circledR}$ ) in a real-life cohort of patients with pSS.

\section{MATERIALS AND METHODS}

\section{Study Population}

This was a retrospective, observational, single-center study of pSS patients receiving RTX off-label in a tertiary Rheumatology Unit (ASL1 Avezzano-Sulmona-L'Aquila and University of L'Aquila, Italy). We included 17 consecutive patients with pSS diagnosis, with a disease duration of $<5$ years and a systemic moderate-high activity (ESSDAI $\geq 5$ ) (36) who received the first RTX infusion between December 2013 and January 2019. 
Patients receiving the first infusion between December 2013 and November 2017 received RTX originator (MabThera ${ }^{\circledR}$ ) (nine patients), and those initiating RTX after November 2017 received CT-P10 (Truxima ${ }^{\circledR}$ ) (eight patients), because of local health policy regulations. Patients with secondary Sjögren's syndrome; severe cardiac, pulmonary, renal or hematologic failure; a history of cancer in the last 5 years; hepatitis B or hepatitis $\mathrm{C}$ infection, human immunodeficiency virus infection, tuberculosis, severe diabetes, and any other chronic disease; or evidence of infection; and if they were unable to understand and to adhere to the treatment were not eligible to start RTX and therefore excluded from this study. Treatment with conventional synthetic disease-modifying antirheumatic drugs (csDMARDs) and corticosteroids was allowed during the study period because of the moderate-high disease activity. However, any change in the dose or schedule was noted.

\section{RTX Administration}

Patients received infusion of $1,000 \mathrm{mg}$ of either RTX originator or CT-P10 at day 1 and at day 15 to complete a course of therapy. This course was repeated after 24 weeks. During the study period, all patients received two courses of therapy with RTX (baseline and week 24). To minimize adverse effects, all patients were pretreated with methylprednisolone (40 mg intravenously), paracetamol (1,000 mg orally), and chlorpheniramine (10 mg intravenously).

\section{Clinical and Laboratory Evaluation}

Clinical and laboratory evaluations were performed at baseline (W0), week 12 (W12), week 24 (W24), week 36 (W36), and week 48 (W48) of treatment. The disease activity was assessed using the ESSDAI and clinical ESSDAI (clinESSDAI), whereas patient-reported outcomes (PROs) included the EULAR Sjögren's Syndrome Patient-Reported Index (ESSPRI) and the patient's assessment of general health $(\mathrm{GH})$ score [on a 0 $100-\mathrm{mm}$ visual analog scale (VAS) with "very poor" and "very well" as anchors]. We also considered the reduction in the daily dose of prednisone. Total lymphocyte count, $\mathrm{CD} 19^{+} \mathrm{B}$ lymphocytes, serum $\gamma$-globulins, immunoglobulin classes (IgG, $\operatorname{IgA}$, and $\operatorname{IgM}$ ) concentration, and serum rheumatoid factor (RF) were regularly measured. Patients were asked to report the occurrence of systemic or local adverse events (AEs) related to treatment at each visit. AEs were judged as serious if they resulted in death, were life-threatening according to the investigator's own judgment, caused hospital admission, resulted in birth defect (from unplanned pregnancies) or disability, or were important medical events that could have jeopardized the patient or needed intervention to prevent another serious $\mathrm{AE}$, or both.

\section{Study Endpoints}

The primary efficacy endpoint of this study was the delta $(\Delta)$ ESSDAI, clinESSDAI, and ESSPRI achieved by CTP10 compared with RTX originator. The primary safety outcome was the number of AEs during the study period. Secondary exploratory endpoints included the percentage
TABLE 1 | Demographic and clinical characteristics of patients at baseline.

\begin{tabular}{|c|c|c|c|}
\hline & $\begin{array}{l}\text { CT-P10 } \\
\text { n (\%) }\end{array}$ & $\begin{array}{l}\text { RTX originator } \\
\text { n (\%) }\end{array}$ & $p$-value \\
\hline Number & 8 & 9 & - \\
\hline Age, mean (SD), years & $60.1(9.1)$ & $51.8(12.8)$ & ns \\
\hline Female gender, $\mathbf{n}(\%)$ & $7(87)$ & $8(89)$ & ns \\
\hline Disease duration, mean (SD), years & $1.29(1.5)$ & $1.75(1.6)$ & ns \\
\hline Focus score $\geq 1, n(\%)$ & $8(100)$ & $9(100)$ & ns \\
\hline Xerostomia, n (\%) & $8(100)$ & $8(89)$ & ns \\
\hline Xerophthalmia, n (\%) & $8(100)$ & $9(100)$ & ns \\
\hline Salivary gland enlargement, $\mathrm{n}(\%)$ & $1(12)$ & $3(33)$ & ns \\
\hline ESSDAI, mean (SD) & $12.0(7.3)$ & $12.6(6.6)$ & ns \\
\hline ClinESSDAI, mean (SD) & $11.4(7.1)$ & $11.4(6.4)$ & ns \\
\hline \multicolumn{4}{|l|}{ ESSDAI domains, n (\%) } \\
\hline Constitutional & $1(12)$ & $6(67)$ & ns \\
\hline Lymphoadenopathy & $3(37)$ & $3(33)$ & ns \\
\hline Glandular & $1(12)$ & $3(33)$ & ns \\
\hline Articular & $8(100)$ & $8(89)$ & ns \\
\hline Cutaneous & $1(12)$ & $1(11)$ & ns \\
\hline Pulmonary & $1(12)$ & $1(11)$ & ns \\
\hline Renal & $0(0)$ & $0(0)$ & ns \\
\hline Muscular & $0(0)$ & $0(0)$ & ns \\
\hline PNS & $3(37)$ & $3(33)$ & ns \\
\hline CNS & $1(12)$ & $0(0)$ & ns \\
\hline Hematological & $0(0)$ & $2(22)$ & ns \\
\hline Biological & $4(50)$ & $7(78)$ & ns \\
\hline Hypergammaglobulinemia, n (\%) & $3(37)$ & $5(55)$ & ns \\
\hline Reduced complement fractions, $n$ (\%) & $2(25)$ & $3(33)$ & ns \\
\hline \multicolumn{4}{|l|}{ Autoantibodies, n (\%) } \\
\hline Neither anti-Ro nor anti-La & $3(37)$ & $5(55)$ & ns \\
\hline Anti-Ro only & $4(50)$ & $2(22)$ & ns \\
\hline Anti-Ro and anti-La & $1(12)$ & $2(22)$ & ns \\
\hline RF & $5(62)$ & $4(44)$ & ns \\
\hline ESSPRI, mean (SD) & $6.8(2.1)$ & $7.8(2.0)$ & ns \\
\hline GH, mean (SD) & $30(16.0)$ & $33.3(22.9)$ & ns \\
\hline csDMARDs, n (\%) & $4(50)$ & $4(44)$ & ns \\
\hline Prednisone, n (\%) & $5(62)$ & $8(89)$ & ns \\
\hline
\end{tabular}

$R T X$, rituximab; SD, standard deviation; ns, not statistically significant; ESSDAI, EULAR Sjögren's syndrome disease activity index; PNS, peripheral nervous system; CNS, central nervous system; RF, rheumatoid factor; ESSPRI, EULAR Sjögren's Syndrome PatientReported Index; GH, global health; csDMARDs, conventional synthetic disease-modifying antirheumatic drugs.

of patients achieving a minimal clinically important improvement (MCII) with ESSDAI (drop of at least three points), MCII with ESSPRI (drop of at least one point or $15 \%$ of baseline value), and patient acceptable symptom state (PASS) (ESSPRI <5) at W48, laboratory measures, and GH.

\section{Statistical Analysis}

IBM SPSS Statistics 23.0 software was used for statistical analysis. One-way analysis of variance and multiple-comparisons post hoc tests were employed to calculate differences between baseline and following timepoints. Differences between the 


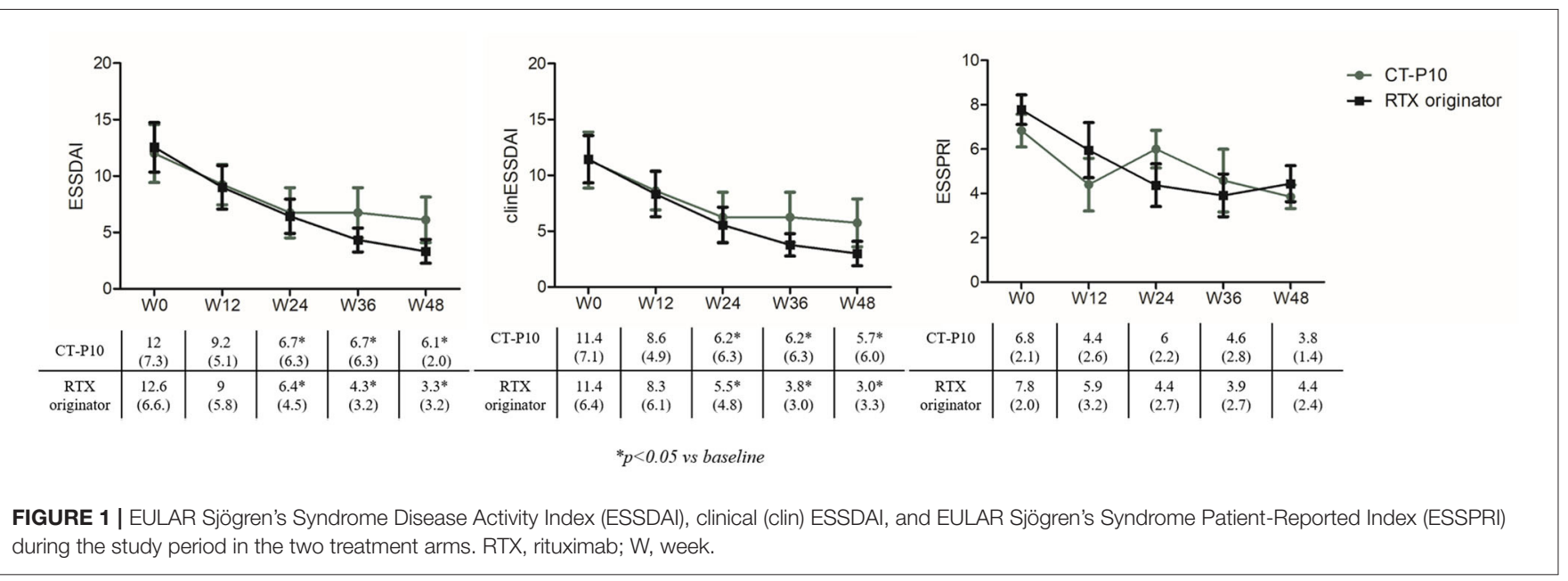

TABLE 2 | Change of disease activity and patient-reported symptoms at the different timepoints compared to baseline.

\begin{tabular}{|c|c|c|c|c|c|c|c|c|}
\hline & \multicolumn{2}{|c|}{ W12 } & \multicolumn{2}{|c|}{ W24 } & \multicolumn{2}{|c|}{ W36 } & \multicolumn{2}{|c|}{ W48 } \\
\hline & CT-P10 & RTX originator & CT-P10 & RTX originator & CT-P10 & RTX originator & CT-P10 & RTX originator \\
\hline$\Delta$ ESSDAl, mean (SD) & $-2.75(2.37)$ & $-3.00(2.18)$ & $-5.12(2.10)$ & $-5.89(4.99)$ & $-5.12(2.10)$ & $-7.67(5.59)$ & $-5.62(2.26)$ & $-8.44(5.03)$ \\
\hline$\Delta$ clinESSDAI mean (SD) & $-2.75(2.37)$ & $-3.11(2.26)$ & $-5.12(2.10)$ & $-5.89(4.99)$ & $-5.12(2.10)$ & $-7.67(5.59)$ & $-5.62(2.26)$ & $-8.44(5.03)$ \\
\hline$\triangle \mathrm{ESSPRI}$ mean (SD) & $-4.1(4.4)$ & $-3.15(3.1)$ & $-1.6(2.3)$ & $-3.3(2.9)$ & $-4.5(2.9)$ & $-4.3(2.6)$ & $-3.46(2.9)$ & $-3.33(0.91)$ \\
\hline
\end{tabular}

RTX, rituximab; ESSDAI, EULAR Sjögren's Syndrome Disease Activity Index; clin, clinical; ESSPRI, EULAR Sjögren's Syndrome Patient-Reported Index.

TABLE 3 | ESSDAl domains in the study cohort at W48.

\begin{tabular}{lccc}
\hline & CT-P10 $\mathbf{n}(\%)$ & RTX originator n (\%) & p-value \\
\hline Number & 8 & 9 & - \\
ESSDAl domains & & & \\
Constitutional & $0(0)$ & $0(0)$ & $\mathrm{ns}$ \\
Lymphoadenopathy & $1(12)$ & $0(0)$ & $\mathrm{ns}$ \\
Glandular & $0(0)$ & $1(11)$ & $\mathrm{ns}$ \\
Articular & $6(75)$ & $5(55)$ & $\mathrm{ns}$ \\
Cutaneous & $0(0)$ & $0(0)$ & $\mathrm{ns}$ \\
Pulmonary & $1(12)$ & $1(11)$ & $\mathrm{ns}$ \\
Renal & $0(0)$ & $0(0)$ & $\mathrm{ns}$ \\
Muscular & $0(0)$ & $0(0)$ & $\mathrm{ns}$ \\
PNS & $3(37)$ & $2(22)$ & $\mathrm{ns}$ \\
CNS & $1(12)$ & $0(0)$ & $\mathrm{ns}$ \\
Hematological & $0(0)$ & $0(0)$ & $\mathrm{ns}$ \\
Biological & $2(25)$ & $2(22)$ & $\mathrm{ns}$ \\
\hline
\end{tabular}

RTX, rituximab; ESSDAI, EULAR Sjögren's Syndrome Disease Activity Index; ns, not statistically significant; PNS, peripheral nervous system; CNS, central nervous system.

demographic and clinical characteristics of the two treatment groups at baseline and between the two treatment arms at each timepoint were tested with non-parametric Mann-Whitney $U$ test. When required, $\chi^{2}$ test was also employed. $P<0.05$ were considered significant.

\section{RESULTS}

\section{Baseline Demographic and Clinical Characteristics}

Demographic and clinical characteristics of the two treatment groups at baseline are shown in Table 1. We included 17 patients: nine in the RTX originator group and eight in the CT-P10 group. We did not observe any significant differences in age, gender, and disease duration, or in clinical and laboratory parameters. None of the included patients displayed B-cell lymhoproliferative disease. The proportion in the use of the different csDMARDs and corticosteroids did not differ in both groups. In detail, three patients were in treatment with methotrexate, one with leflunomide, and six with hydroxychloroquine. Eight patients in the RTX originator group and five patients in the CT-P10 group were also in treatment with prednisone (mean dosage at baseline 6.3 and $4.2 \mathrm{mg}$, respectively). All 17 patients completed the 12 months' follow-up and are still in treatment.

\section{Primary Endpoints}

Figure 1 shows ESSDAI, clinESSDAI, and ESSPRI across the study period. In both treatment groups, ESSDAI and clinESSDAI started to decrease by W12, albeit significantly only from W24. The significant difference with baseline was consistent up to W48; at none of the timepoints the $\triangle$ ESSDAI and $\triangle$ clinESSDAI were significantly different between the two treatment arms (Table 2). At W48, MCII with ESSDAI were achieved by all patients regardless of the treatment arm. Table 3 shows the improvement within each ESSDAI domain in the two 


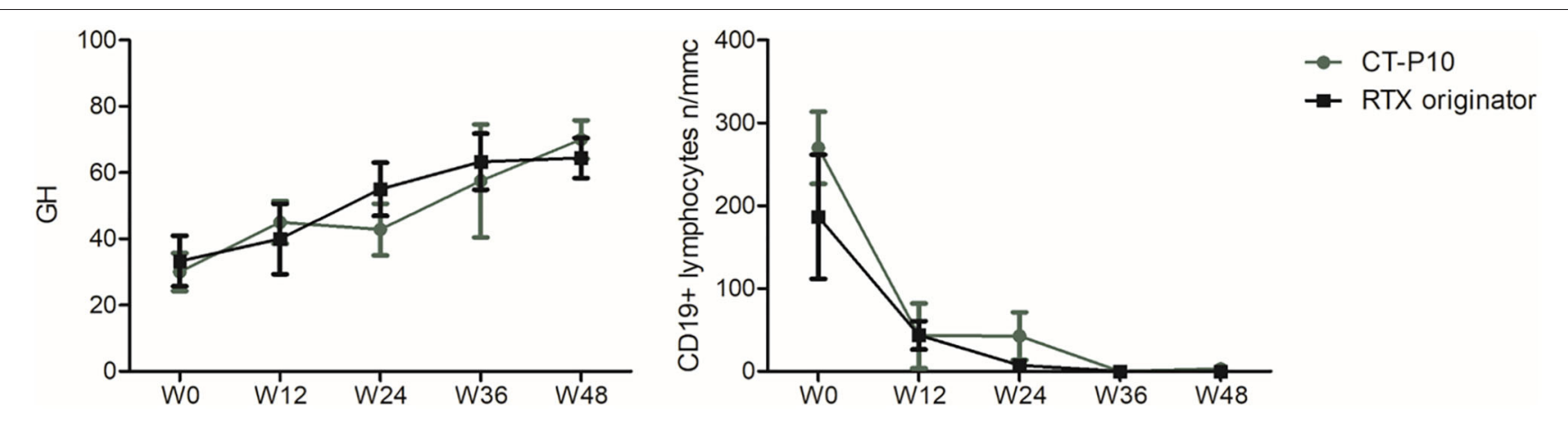

FIGURE 2 | Global health (GH) and CD19+ lymphocyte count during the study period in the two treatment arms. W, week.

treatment groups at W48. Improvement was predominantly seen in constitutional, lymphoadenopathy, glandular, articular, hematological, and biological domains, and still the two cohorts did not display any difference in this regard. In addition, all the five patients (three in the originator group and two in the CT-P10 group) with reduced complement fractions at baseline still displayed it at W48. With regard to ESSPRI, neither CTP10 nor RTX originator was able to significantly reduce it in line with previous studies (Figure 1), and no difference could be observed with regard to the $\triangle$ ESSPRI between the two treatment groups at any timepoint (Table 2). However, MCII with ESSPRI (reduction of at least one point or reduction of $15 \%$ of baseline value) was achieved at W48 by six patients (75\%) in the CT-P10 group and all nine patients (100\%) in the RTX originator group (not statistically significant). PASS was achieved by a similar proportion of patients in the two treatment groups (CT-P10 group: $n=4$; $50 \%$; RTX originator: $n=4 ; 44 \%$; not statistically significant) at W48.

As far as the safety is concerned, a total of four AEs were recorded in four patients across the 12 months' follow-up: one mild cutaneous reaction (RTX originator group, T6) and three upper airways infections (CT-P10 group, one at T3 and one at T9; RTX originator group, T6), which required antibiotic therapy.

\section{Secondary Clinical and Laboratory Outcomes}

$\mathrm{GH}$ showed a trend toward improvement starting from W12 in both groups and becoming significant at W48 compared to baseline, with no significant differences in the two groups (RTX originator group W0: $33.3 \pm 22.9$, W48: $70 \pm 17.89 ; p$ $=0.01$; CT-P10 group W0: $30 \pm 16$, W48: $76.7 \pm 11.5 ; p=$ 0.02) (Figure 2). Both RTX originator and CT-P10 effectively depleted circulating B lymphocytes as demonstrated by the serial measurement of $\mathrm{CD} 19^{+}$cells (Figure 2). The total lymphocyte count, however, remained unaffected (data not shown). Serum $\gamma$ globulins, immunoglobulin classes (IgG, IgA, and IgM) and RF were regularly monitored and did not show significant changes overtime (data not shown).

The majority of patients taking corticosteroids at baseline tapered the dose until withdrawal with only two out of five patients in the CT-P10 group and five out of eight patients in the RTX originator group still on treatment (mean dose $3 \mathrm{mg}$ in both groups).

\section{DISCUSSION}

This is the first study demonstrating that CT-P10 and RTX originator show similar efficacy and safety profiles in pSS patients with moderate-high disease activity and disease duration of $<5$ years at 48 weeks of follow-up. Concerning the clinical efficacy, in both treatment groups, ESSDAI and clinESSDAI started to slowly decrease by W12, with a significant difference with baseline starting from W24 and remaining sustained up to W48. Furthermore, we did not observe any significant differences in the $\triangle$ ESSDAI, $\triangle$ clinESSDAI, and MCII with ESSDAI between the two treatment arms. Interestingly, this improvement mirrored the dose reduction of prednisone, with its withdrawal in three patients in both groups at W48. In addition, in our cohort, the ESSDAI domains were mainly represented by articular, lymphoadenopathy, and peripheral nervous system involvement in both groups and constitutional in originator. Therefore, our study confirms existing evidence that RTX may be considered a valuable therapeutic option in patients with this specific phenotype. However, despite the generally acknowledged beneficial effects of RTX treatment on biological parameters, clinical outcomes vary between studies (20). Available data on the systemic efficacy of RTX in pSS come from large studies that included more than 400 patients, and the predominant regimen of administration was two doses of $1,000 \mathrm{mg}$ each administered 15 days apart $(8,9)$. The great majority of these studies showed efficacy in at least one of the systemic outcomes analyzed, considering global response, organspecific response, ESSDAI reduction, or prednisone reduction, thereby providing a reasonable rationale for the use of this therapy in specific clinical settings. These concepts have been incorporated in the recent EULAR recommendations for the management of Sjögren's syndrome with topical and systemic therapies that reserve the use of RTX to patients with severe refractory disease $(8,9)$. PROs with VAS have been used in most studies, including two recent large RCTs $(14,15)$ to assess subjective symptoms. Devauchelle-Pensec et al. (14) found no significant results in the primary outcome $(\geq 30-\mathrm{mm}$ 
improvement at week 24 on at least two out of four VAS scores-dryness, fatigue, pain, global, 23 vs. $22 \%$; $p=0.91$ ), whereas Bowman et al. (15) found no significant results in the primary outcome (reduction $\geq 30 \%$ at week 48 in either fatigue or oral dryness VAS, RTX 39.3 vs. placebo $36.8 \%$; $p$ $=0.76)$. This is in line with our findings revealing a failure in achieving a significant reduction of ESSPRI up to W48. Of interest, despite a considerable proportion of patients reached MCII with ESSPRI at W48, namely, a reduction of at least one point or $15 \%$ reduction of baseline value, approximately only half of them in each treatment group achieved a PASS, namely, an ESSPRI of $<5$. In our study, both treatments also induced a similar improvement of $\mathrm{GH}$, which based on the ESSDAI and ESSPRI values overtime seemed to be more related to systemic disease activity rather than sicca symptoms, fatigue, or pain.

The number of patients underreporting or overreporting their symptoms may influence the results of studies and underscores the uniqueness of individual perception of pSSrelated symptoms regardless of disease activity and therefore showing different response patterns to RTX treatment. In this regard, the discrepancy between PROs, objective measurement of glandular function, and systemic disease activity indexes in pSS underpins that they represent complementary perspectives to obtain a holistic view of the individual, and therefore, all of them should be explored and implemented in clinical practice (37). With regard to the effect on $\mathrm{B}$ cells, we confirmed that treatment with RTX leads to a nearly complete depletion in the peripheral blood, without any significant differences between the two treatment groups $(12,16)$. Although we did not observe any change in serum RF, $\gamma$ globulins, and immunoglobulin classes, it has been postulated that by interfering with B-cell activation likely one aspect contributing to the amelioration of systemic disease activity in pSS patients may be the lower levels of autoantibodies and proinflammatory cytokines (38). CT-P10 was the first RTX biosimilar (39) and could represent a cost-effective and safe therapeutic alternative to RTX originator, possibly facilitating access to therapy for pSS patients with severe, refractory systemic disease.

Budget impact analysis models estimated the expected changes in expenditure that would occur as a result of the adoption of a new therapeutic intervention. On this basis, it was demonstrated that introduction of CT-P10 could be associated with significant budget savings in European Union countries, for both in-label and off-label indications (40). With the expiry date of patent protection approaching for several originator biologic DMARDs, we have witnessed the development of less expensive competitor products of sufficient similarity, called biosimilars. Regulatory approval is based on the totality of evidence for biosimilarity derived from a comprehensive comparability exercise with the reference medicine (41). This comparability exercise includes extensive physicochemical and structural evaluations, as well as data from preclinical and clinical pharmacokinetic, pharmacodynamic, and immunogenicity assessments. The final step in the development process is confirmatory phase III clinical trial in patients with the specific disease. However, in line with regulatory requirements, approval of CT-P10 in some indications of RTX was based in part on the extrapolation of clinical data collected in other indications, plus a scientific justification based on the consistency of RTX mechanisms of action across indications (42-44). Although there are several discrepancies in assessing and reporting immunogenicity data of biosimilars for CD20 inhibitors, data collected in trials confirmed that immunogenicity parameters of CT-P10 were similar to those of its reference product $(26,27,30)$. Furthermore, it was reassuring to observe that the safety profile of CT-P10 was similar to RTX originator also in pSS, with upper airway infections being the most frequent AEs in both groups.

We acknowledge that this study displays some limitations including the retrospective nature, the heterogeneity of clinical spectrum and disease duration, and the small number of patients. In addition, treatment choice between RTX originator and CT-P10 depended on the time of the first infusion and not the physician's decision, because of local health policy issues. Notwithstanding, we believe that given the lack of studies on CTP10 in pSS, it provides important insight to clinicians who will be required to use this compound in pSS patients.

\section{CONCLUSION}

RTX originator is a cornerstone in therapeutic strategies for rheumatic diseases, including pSS; however, economic issues may be a major barrier to access the best available care, particularly in some countries. Therefore, the use of biosimilars can only be expected to increase. Whether the use of biosimilars will be of greater benefit from a societal perspective will depend on their cost-effectiveness and safety. In this perspective, the collection of efficacy and safety data for all in-label and off-label indications is of paramount importance to identify and tackle potential differences among compounds and ultimately does not affect the quality of care for patients with pSS.

\section{DATA AVAILABILITY STATEMENT}

All datasets generated for this study are included in the article/supplementary material.

\section{ETHICS STATEMENT}

Ethical review and approval was obtained in accordance with local legislation and institutional requirements. The patients/participants provided their written informed consent to participate in this study.

\section{AUTHOR CONTRIBUTIONS}

All authors drafted and approved the final version of the manuscript. 


\section{REFERENCES}

1. Vivino FB, Bunya VY, Massaro-Giordano G, Johr CR, Giattino SL, Schorpion A, et al. Sjögren's syndrome: an update on disease pathogenesis, clinical manifestations and treatment. Clin Immunol. (2019) 203:81121. doi: 10.1016/j.clim.2019.04.009

2. Alunno A, Carubbi F, Bartoloni E, Cipriani P, Giacomelli R, Gerli R. The kaleidoscope of neurological manifestations in primary Sjögren's syndrome. Clin Exp Rheumatol. (2019) 37(Suppl. 118):192-8.

3. Cafaro G, Croia C, Argyropoulou OD, Leone MC, Orlandi M, Finamore F, et al. One year in review 2019:Sjögren's syndrome. Clin Exp Rheumatol. (2019) 37(Suppl. 118):3-15.

4. Alunno A, Leone MC, Giacomelli R, Gerli R, Carubbi F. Lymphoma and lymphomagenesis in primary Sjögren's syndrome. Front Med. (2018) 5:102. doi: 10.3389/fmed.2018.00102

5. Carubbi F, Alunno A, Cipriani P, Di Benedetto P, Ruscitti P, Berardicurti $\mathrm{O}$, et al. Is minor salivary gland biopsy more than a diagnostic tool in primary Sjögren?s syndrome? Association between clinical, histopathological, and molecular features: a retrospective study. Semin Arthritis Rheum. (2014) 44:314-24. doi: 10.1016/j.semarthrit.2014.05.015

6. Carubbi F, Alunno A, Cipriani P, Bartoloni E, Baldini C, Quartuccio L, et al. A retrospective, multicenter study evaluating the prognostic value of minor salivary gland histology in a large cohort of patients with primary Sjögren's syndrome. Lupus. (2015) 24:315-20. doi: 10.1177/096120331 4554251

7. Carubbi F, Alunno A, Cipriani P, Coletti G, Bigerna B, Manetti M, et al. Different operators and histologic techniques in the assessment of germinal center-like structures in primary Sjögren's syndrome minor salivary glands. PLoS ONE. (2019) 14:e0211142. doi: 10.1371/journal.pone.0211142

8. Ramos-Casals M, Brito-Zerón P, Bombardieri S, Bootsma H, De Vita S, Dörner T, et al. EULAR recommendations for the management of Sjögren's syndrome with topical and systemic therapies. Ann Rheum Dis. (2020) 79:318. doi: 10.1136/annrheumdis-2019-216114

9. Brito-Zerón P, Retamozo S, Kostov B, Baldini C, Bootsma H, De Vita $\mathrm{S}$, et al. Efficacy and safety of topical and systemic medications: a systematic literature review informing the EULAR recommendations for the management of Sjögren's syndrome. RMD Open. (2019) 5:e001064. doi: 10.1136/rmdopen-2019-001064

10. Carubbi F, Alunno A, Cipriani P, Bartoloni E, Ciccia F, Triolo G, et al. Rituximab in primary Sjögren's syndrome: a ten-year journey. Lupus. (2014) 23:1337-49. doi: 10.1177/0961203314546023

11. Kaegi C, Wuest B, Schreiner J, Steiner UC, Vultaggio A, Matucci A, et al. Systematic review of safety and efficacy of rituximab in treating immune-mediated disorders. Front Immunol. (2019) 10:1990. doi: 10.3389/fimmu.2019.01990

12. Meijer JM, Meiners PM, Vissink A, Spijkervet FK, Abdulahad W, Kamminga $\mathrm{N}$, et al. Effectiveness of rituximab treatment in primary Sjögren's syndrome: a randomized, doubleblind, placebo-controlled trial. Arthritis Rheum. (2010) 62:960-8. doi: 10.1002/art.27314

13. Dass S, Bowman SJ, Vital EM, Ikeda K, Pease CT, Hamburger J, et al. Reduction of fatigue in Sjögren's syndrome with rituximab: results of a randomised, double-blind, placebo-controlled pilot study. Ann Rheum Dis. (2008) 67:1541-4. doi: 10.1136/ard.2007.083865

14. Devauchelle-Pensec V, Mariette X, Jousse-Joulin S, Berthelot JM, Perdriger A, Puéchal X, et al. Treatment of primary Sjögren's syndrome with rituximab: a randomized trial. Ann Intern Med. (2014) 160:233-42. doi: 10.7326/M13-1085

15. Bowman SJ, Everett CC, Dwyer JL, Emery P, Pitzalis C, Ng WF, et al. Randomized controlled trial of rituximab and cost-effectiveness analysis in treating fatigue and oral dryness in primary Sjögren's syndrome. Arthritis Rheumatol. (2017) 69:1440-50. doi: 10.1002/art.40093

16. Pijpe J, van Imhoff GW, Spijkervet FK, Roodenburg JL, Wolbink GJ, Mansour K, et al. Rituximab treatment in patients with primary Sjögren's syndrome: an open-label phase II study. Arthritis Rheum. (2005) 52:274050. doi: 10.1002/art.21260

17. Devauchelle-Pensec V, Pennec Y, Morvan J, Pers JO, Daridon C, Jousse-Joulin $\mathrm{S}$, et al. Improvement of Sjögren's syndrome after two infusions of rituximab (anti-CD20). Arthritis Rheum. (2007) 57:310-7. doi: 10.1002/art.22536
18. St Clair EW, Levesque MC, Prak ET, Vivino FB, Alappatt CJ, Spychala $\mathrm{ME}$, et al. Rituximab therapy for primary Sjögren's syndrome: an openlabel clinical trial and mechanistic analysis. Arthritis Rheum. (2013) 65:1097106. doi: 10.1002/art.37850

19. Carubbi F, Cipriani P, Marrelli A, Benedetto P, Ruscitti P, Berardicurti O, et al. Efficacy and safety of rituximab treatment in early primary Sjögren's syndrome: a prospective, multicenter, follow-up study. Arthritis Res Ther. (2013) 15:R172. doi: 10.1186/ar4359

20. Grigoriadou S, Chowdhury F, Pontarini E, Tappuni A, Bowman SJ, Bombardieri M. B cell depletion with rituximab in the treatment of primary Sjögren's syndrome: what have we learnt? Clin Exp Rheumatol. (2019) 37(Suppl. 118):S217-24.

21. https://www.ema.europa.eu/en/medicines/human/EPAR/mabthera

22. https://www.accessdata.fda.gov/drugsatfda_docs/label/2019/103705s5457lbl. pdf

23. https://www.ema.europa.eu/en/medicines/human/EPAR/truxima

24. Stebbing J, Mainwaring PN, Curigliano G, Pegram M, Latymer M, Bair $\mathrm{AH}$, et al. Understanding the role of comparative clinical studies in the development of oncology biosimilars. J Clin Oncol. (2020) 38:107080. doi: 10.1200/JCO.19.02953

25. Jurczak W, Cohen S, Illidge TM, Silva AD, Amersdorffer J. Scientific rationale underpinning the development of biosimilar rituximab in hematological cancers and inflammatory diseases. Future Oncol. (2019) 15:4223-34. doi: 10.2217/fon-2019-0430

26. Yoo DH, Suh CH, Shim SC, Jeka S, Cons-Molina FF, Hrycaj P, et al. A multicentre randomised controlled trial to compare the pharmacokinetics, efficacy and safety of CT-P10 and innovator rituximab in patients with rheumatoid arthritis. Ann Rheum Dis. (2017) 76:566-70. doi: 10.1136/annrheumdis-2016-209540

27. Park W, Suh CH, Shim SC, Molina FFC, Jeka S, Medina-Rodriguez FG, et al. Efficacy and safety of switching from innovator rituximab to biosimilar CT-P10 compared with continued treatment with CT-P10: results of a 56week open-label study in patients with rheumatoid arthritis. BioDrugs. (2017) 31:369-77. doi: 10.1007/s40259-017-0233-6

28. Yoo DH, Suh CH, Shim SC, Jeka S, Molina FFC, Hrycaj P, et al. Efficacy, safety and pharmacokinetics of up to two courses of the rituximab biosimilar CTP10 versus innovator rituximab in patients with rheumatoid arthritis: results up to week 72 of a phase I randomized controlled trial. BioDrugs. (2017) 31:357-67. doi: 10.1007/s40259-017-0232-7

29. Kim WS, Buske C, Ogura M, Jurczak W, Sancho JM, Zhavrid E, et al. Efficacy, pharmacokinetics, and safety of the biosimilar CTP10 compared with rituximab in patients with previously untreated advanced-stage follicular lymphoma: a randomised, double-blind, parallelgroup, non-inferiority phase 3 trial. Lancet Haematol. (2017) 4:e36273. doi: 10.1016/S2352-3026(17)30120-5

30. Park W, BoŽić-Majstorović L, Milakovic D, Berrocal Kasay A, El-Khouri EC, Irazoque-Palazuelos F, et al. Comparison of biosimilar CT-P10 and innovator rituximab in patients with rheumatoid arthritis: a randomized controlled Phase 3 trial. MAbs. (2018) 10:934-43. doi: 10.1080/19420862.2018.1487912

31. Ogura M, Sancho JM, Cho SG, Nakazawa H, Suzumiya J, Tumyan $\mathrm{G}$, et al. Efficacy, pharmacokinetics, and safety of the biosimilar CT-P10 in comparison with rituximab in patients with previously untreated low-tumour-burden follicular lymphoma: a randomised, double-blind, parallel-group, phase 3 trial. Lancet Haematol. (2018) 5:e543-53. doi: 10.1016/S2352-3026(18)30157-1

32. Suh CH, Yoo DH, Berrocal Kasay A, Chalouhi El-Khouri E, Cons Molina FF, Shesternya P, et al. Long-term efficacy and safety of biosimilar CT-P10 versus innovator rituximab in rheumatoid arthritis: 48-week results from a randomized phase III trial. BioDrugs. (2019) 33:7991. doi: 10.1007/s40259-018-00331-4

33. Shim SC, BoŽić-Majstorović L, Berrocal Kasay A, El-Khouri EC, IrazoquePalazuelos F, Cons Molina FF, et al. Efficacy and safety of switching from rituximab to biosimilar CT-P10 in rheumatoid arthritis: 72-week data from a randomized phase 3 trial. Rheumatology. (2019) 58:2193202. doi: 10.1093/rheumatology/kez152

34. Otremba B, Borchardt J, Kuske A, Hollnagel-Schmitz M, Losch FO. Real-world use and acceptance of rituximab biosimilars in non-Hodgkin 
lymphoma in an oncologist network in Germany. Future Oncol. (2020) 16:1001-12. doi: 10.2217/fon-2020-0180

35. Lee K, Ha JY, Jung AR, Lee YS, Lee SW, Ryu JS, et al. The clinical outcomes of rituximab biosimilar CT-P10 (Truxima $($ ) with $\mathrm{CHOP}$ as first-line treatment for patients with diffuse large B-cell lymphoma: real-world experience. Leuk Lymphoma. (2020) 15:1-9. doi: 10.1080/10428194.2020.1742906

36. Seror R, Bootsma H, Saraux A, Bowman SJ, Theander E, Brun JG, et al. Defining disease activity states and clinically meaningful improvement in primary Sjögren's syndrome with EULAR primary Sjögren's syndrome disease activity (ESSDAI) and patient-reported indexes (ESSPRI). Ann Rheum Dis. (2016) 75:382-9. doi: 10.1136/annrheumdis-2014-206008

37. Alunno A, Bartoloni E, Valentini V, La Paglia GMC, Valentini E, Leone MC, et al. Discrepancy between subjective symptoms, objective measures and disease activity indexes: the lesson of primary Sjögren's syndrome. Clin Exp Rheumatol. (2018) 36(Suppl. 112):210-4.

38. Verstappen GM, van Nimwegen JF, Vissink A, Kroese FGM, Bootsma H. The value of rituximab treatment in primary Sjögren's syndrome. Clin Immunol. (2017) 182:62-71. doi: 10.1016/j.clim.2017.05.002

39. Deeks ED. CT-P10 (Truxima ${ }^{\mathrm{TM}}$ ): a rituximab biosimilar. BioDrugs. (2017) 31:275-8. doi: 10.1007/s40259-017-0226-5

40. Gulácsi L, Brodszky V, Baji P, Rencz F, Péntek M. The rituximab biosimilar CT-P10 in rheumatology and cancer: a budget impact analysis in 28 European countries. Adv Ther. (2017) 34:1128-44. doi: 10.1007/s12325-0170522-y

41. Strand V, Gonçalves J, Hickling TP, Jones HE, Marshall L, Isaacs JD. Immunogenicity of biosimilars for rheumatic diseases, plaque psoriasis, and inflammatory bowel disease: a review from clinical trials and regulatory documents. BioDrugs. (2020) 34:27-37. doi: 10.1007/s40259-019-00394-x

42. Schioppo $\mathrm{T}$, Ingegnoli $\mathrm{F}$. Current perspective on rituximab in rheumatic diseases. Drug Des Devel Ther. (2017) 11:2891904. doi: 10.2147/DDDT.S139248

43. Jung JY, Kim JW, Kim HA, Suh CH. Rituximab biosimilar CT-P10 for the treatment of rheumatoid arthritis. Expert Opin Biol Ther. (2019) 19:97986. doi: 10.1080/14712598.2019.1665018

44. Coiffier B. Pharmacokinetics, efficacy and safety of the rituximab biosimilar CT-P10. Expert Rev Clin Pharmacol. (2017) 10:92333. doi: 10.1080/17512433.2017.1359537

Conflict of Interest: The authors declare that the research was conducted in the absence of any commercial or financial relationships that could be construed as a potential conflict of interest.

The reviewer EB declared a shared affiliation, though no other collaboration, with one of the authors AA to the handling editor.

Copyright (c) 2020 Pavlych, Di Muzio, Alunno and Carubbi. This is an open-access article distributed under the terms of the Creative Commons Attribution License (CC $B Y)$. The use, distribution or reproduction in other forums is permitted, provided the original author(s) and the copyright owner(s) are credited and that the original publication in this journal is cited, in accordance with accepted academic practice. No use, distribution or reproduction is permitted which does not comply with these terms. 